Research Article

Human and Medical Genetics

\title{
Resistance mutations of NS3 and NS5b in treatment-naïve patients infected with hepatitis C virus in Santa Catarina and Rio Grande do Sul states, Brazil
}

\author{
Elisabete Andrade ${ }^{1,2}$, Daniele Rocha ${ }^{1}$, Marcela Fontana-Maurell ${ }^{1}$, Elaine Costa $^{1}$, Marisa Ribeiro ${ }^{1}$, Daniela \\ Tupy de Godoy ${ }^{1}$, Antonio G. P. Ferreira ${ }^{1}$, Amilcar Tanuri ${ }^{2}$, Rodrigo Brindeiro ${ }^{2}$ and Patrícia Alvarez ${ }^{1}$ (iD \\ ${ }^{1}$ Fundação Oswaldo Cruz/Fiocruz, Instituto de Tecnologia em Imunobiológicos Bio-Manguinhos, Rio de \\ Janeiro, RJ, Brazil. \\ ${ }^{2}$ Universidade Federal do Rio de Janeiro (UFRJ), Rio de Janeiro, RJ, Brazil.
}

\begin{abstract}
Hepatitis $\mathrm{C}$ virus (HCV) infection is a worldwide health problem. Nowadays, direct-acting antiviral agents (DAAs) are the main treatment for HCV; however, the high level of virus variability leads to the development of resistance-associated variants (RAVs). Thus, assessing RAVs in infected patients is important for monitoring treatment efficacy. The aim of our study was to investigate the presence of naturally occurring resistance mutations in HCV NS3 and NS5 regions in treatment-naïve patients. Ninety-six anti-HCV positive serum samples from blood donors at the Center of Hematology and Hemotherapy of Santa Catarina State (HEMOSC) were collected retrospectively in 2013 and evaluated in this study. HCV 1a (37.9\%), 1b (25.3\%), and 3a (36.8\%) subtypes were found. The frequency of patients with RAVs in our study was $6.9 \%$. The HCV NS5b sequencing reveled 1 sample with L320F mutation and 4 samples with the C316N/R polymorphism. The analysis of the NS3 region revealed the D168A/G/T (3.45\%), S122G (1.15\%), and V55A (2.3\%) mutations. All samples from genotype 3a (36.8\%) presented the V170 I/V non-synonymous mutation. In conclusion, we have shown that mutations in NS3 and NS5b genes are present in Brazilian isolates from therapy-naïve HCV patients.
\end{abstract}

Keywords: Direct-acting antivirals, resistance-associated substitutions, blood donors, NS3, NS5b.

Received: August 24, 2018; Accepted: March 01, 2019.

\section{Introduction}

Hepatitis $\mathrm{C}$ virus (HCV) infection is a worldwide health problem. According to the Global Hepatitis Report, from the World Health Organization (WHO), approximately 71 million people have chronic HCV infection, and nearly 399,000 people die each year, mostly due to cirrhosis or hepatocellular carcinoma (WHO, 2017). HCV has a high genetic heterogeneity and is classified into seven genotypes (1 to 7) and 67 subtypes (Smith et al., 2014). The genotype distribution depends on geographical location and risk groups (Cantaloube et al., 2005). Genotype 1 is the most frequent in Brazil, followed by genotypes 3 and 2 (Campiotto et al., 2005; Lampe et al., 2013).

There is no vaccine available for preventing $\mathrm{HCV}$ infections. The main antiviral treatment until 2011, was PEGylated interferon-alfa ( $\alpha$ Peg-IFN) alone or in combination with ribavirin, leading to a sustained virological response (SVR) in $50 \%$ of treated patients, depending on the virus genotype causing the $\mathrm{HCV}$ infection (Peres-da-Silva

Send correspondence to Patrícia Alvarez, Fundação Oswaldo Cruz/Fiocruz, Instituto de Tecnologia em Imunobiologia Bio-Manguinhos, Avenida Brasil 4365, Rio de Janeiro, RJ, Brazil. E-mail: palvarez@bio.fiocruz.br. et al., 2012; Paolucci et al., 2013; Gross et al., 2018). Nowadays, direct-acting antiviral agents (DAAs) have been approved for HCV infection treatment, with an average SVR above 95\%, at least for genotypes 1 and 4 (Leuw and Stephan, 2018). In Brazil, DAAs were incorporated by the Ministry of Health for the treatment of hepatitis $\mathrm{C}$ under the Unified Health System (SUS) since 2015 (Ministério da Saúde, 2018). Unfortunately, there is little data about the efficacy of DAAs in Brazil, with some information found in the study by Sette Jr et al. (2017).

The primary targets of DAAs are nonstructural proteins essentials for HCV replication, which include the NS3 protease, NS5B polymerase, and NS5A protein (Paolucci et al., 2013; Lontok et al., 2015). However, a challenge in $\mathrm{HCV}$ treatment is the emergence of viral resistance mutations that reduces susceptibility of the virus to DAA therapies (Hoffmann et al., 2015; Gededzha et al., 2017). The development of resistance-associated variants (RAVs) is due to the high level of virus variability, from the combination of the virus' high replication rate, low RNA polymerase fidelity rate, and selective pressure for drug or immunomediated treatment (Peres-da-Silva et al., 2012; Paolucci et al., 2013; Gededzha et al., 2017). 
The presence of RAVs in patients not yet under treatment has been reported previously in different countries (Peres-da Silva et al., 2010; Paolucci et al., 2013; Zeminian et al., 2013; Gededzha et al., 2017). In addition, a systematic review regarding HCV resistance-associated substitutions and their clinical relevance was published recently (Sorbo et al., 2018). Therefore, assessing RAVs in infected patients is important for monitoring the efficacy of therapy (Loggi et al., 2017) and the epidemiology of HCV in Brazil. Thus, the aim of our study was to investigate the presence of naturally occurring resistance mutations in HCV NS3 and NS5 regions in treatment-naïve patients.

\section{Materials and Methods}

The Center of Hematology and Hemotherapy of Santa Catarina State (HEMOSC) is currently responsible for the nucleic acid testing for HIV, HCV, and HBV in samples from blood donors from Santa Catarina and Rio Grande do Sul states. Annually, HEMOSC receives around 300 thousand blood donations. A total of 96 samples that were positive for HCV in 2013 were used for this study, retrospectively.

HCV RNA was extracted from plasma previously conserved at $-80^{\circ} \mathrm{C}$ using a molecular biology workstation (BioRobot MDx, Qiagen), with the Qiamp one-for-all nucleic acid kit (Qiagen), according to the manufacturer's in- structions. Plasma HCV RNA was quantified using COBAS/Taqman HCV Test v2.0 (Roche).

Genotyping/subtyping was performed by amplifying and sequencing a 339-bp amplicon of the NS5b region, according to Cantaloube et al. (2005). The nucleotide sequences obtained were analyzed in the Geno2pheno $[\mathrm{HCV}]$ (Kalaghatgi et al., 2016) for genotypes and subtypes, and possible resistance against licensed DAAs.

The amplification of the entire NS3 region of the HCV genome, followed by a second PCR was performed as described previously (Peres-da-Silva et al., 2010), using primers specific to subtypes $1 \mathrm{a}, 1 \mathrm{~b}$, and $3 \mathrm{a}$. The nucleotide sequences obtained from each subtype were analyzed for drug resistance in the Geno2pheno ${ }_{[\mathrm{HCV}]}$ (Kalaghatgi et al., 2016).

The statistical program SPSS (IBM SPSS Statistics Base 22.0) was used. Multivariate analysis of variance (ANOVA) was applied to compare means of continuous variables with normal distribution $(p<0.05)$.

\section{Results and Discussion}

From the $96 \mathrm{HCV}$-positive samples collected, nine did not have enough material to perform the assays and were excluded from the analysis. Eighty-seven samples were used for genotyping and analysis of NS3 and NS5b regions.

From the 87 samples evaluated, 33 (37.9\%) were of genotype 1a, $22(25.3 \%)$ were of genotype $1 \mathrm{~b}$, and 32

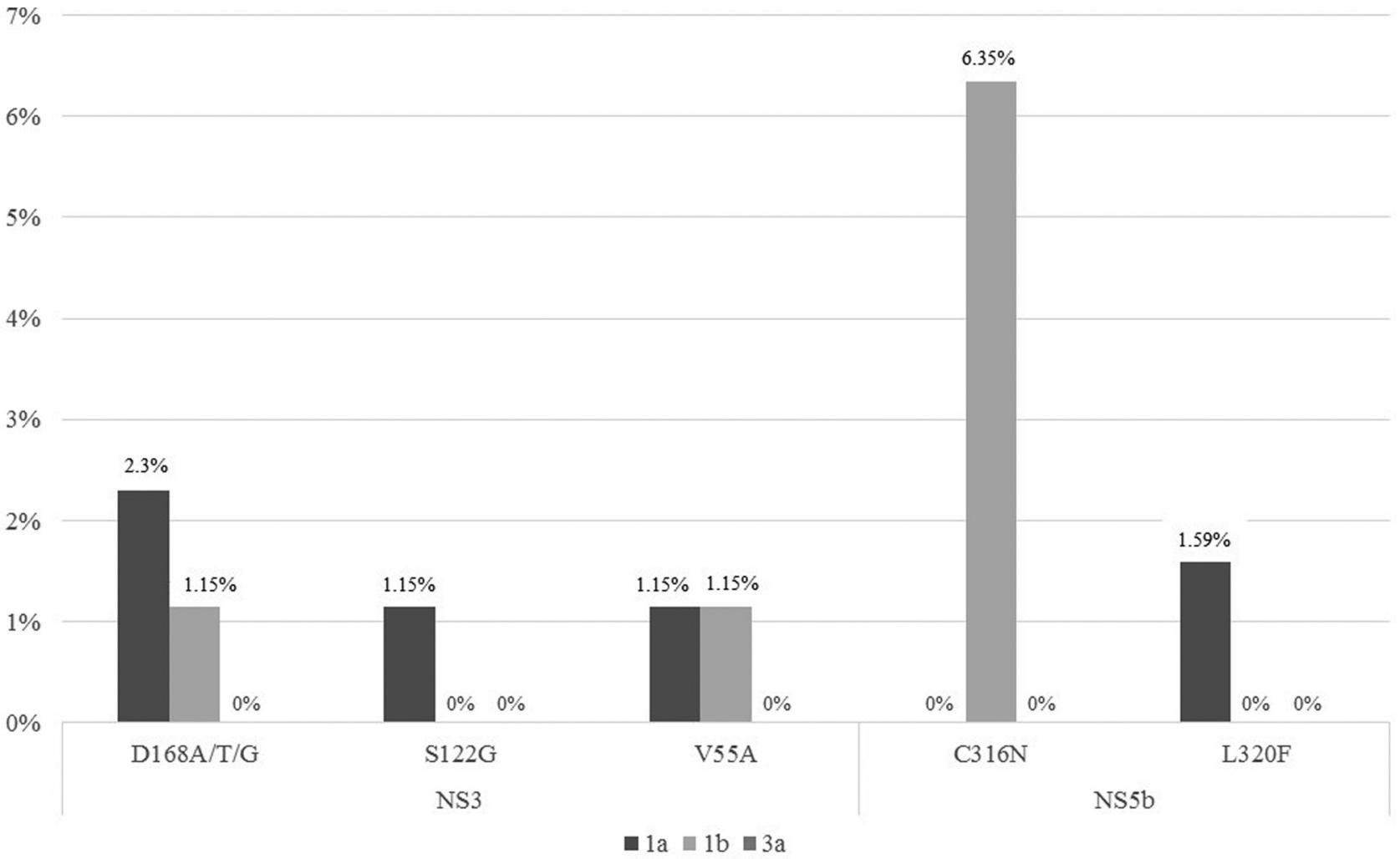

Figure 1 - Frequency of specific NS3 and NS5b resistance-associated variants found in this study by HCV subtype. 
(36.8\%) were of genotype 3a. Genotype 1 (1a plus 1b) was the most frequent, followed by genotype 3 , a result that is in agreement with what was previously reported in Brazil (Campiotto et al., 2005; Lampe et al., 2013; Nishiya et al., 2014). We did not find genotypes 2,4 , and 5 , known to be less frequent in Brazil. Sixty-three samples were successfully geno- and subtyped by the NS3 and NS5b region, and there was no disagreement between the HCV genotypes in both regions. Twenty-four samples had no amplification of the NS5b region, even with an alternative protocol (Sandres-Sauné et al., 2003), and were thus genotyped according to Peres-da-Silva (2010) protocol (NS3 region). This amplification divergence has already been discussed in Larrat et al. (2013), who reported a failure of some quantitative RT-PCR assays to detect or amplify correctly the $\mathrm{NS} 5 \mathrm{~b}$ region in some strains of $\mathrm{HCV}$, even when using three sets of primers covering two different regions. This could be explained by the great variety of viruses, the use of primers not suitable for these peculiar strains, or by a mixed infection in the plasma sample.

The mean viral loads were $5.31 \log \mathrm{IU} / \mathrm{mL}$ for genotype 1a, $5.18 \log \mathrm{IU} / \mathrm{mL}$ for $1 \mathrm{~b}$, and $5.38 \log \mathrm{IU} / \mathrm{mL}$ for $3 \mathrm{a}$. There was no difference in viral load between the genotypes $(p=0.6)$. The detected HCV genotypes and viral loads are both important predictors for therapeutic outcomes. It has been reported that patients infected with genotype 1 are more likely to have higher viral loads than those infected with genotype 2 and 3 (Scott et al., 2007; Soriano et al., 2008; Nishiya et al., 2014). In contrast to our results, in a study carried out with blood donors from São Paulo, the viral load from genotype $3 \mathrm{a}(5.22 \log 10 \mathrm{IU} / \mathrm{mL})$ had a lower $\log$ mean than genotype $1 \mathrm{a}(5.99 \log 10 \mathrm{IU} / \mathrm{mL})(p=0.0002)$ and genotype $1 \mathrm{~b}(6.35 \log 10 \mathrm{IU} / \mathrm{mL})$ (Nishiya et al., 2014), in agreement with a previous report.

The frequency of patients with RAVs in our study $(6.9 \%)$ was intermediate when compared with other Brazilian studies among HCV chronic carriers not treated with protease inhibitors (3.2\% - 18.9\%) (Hoffmann et al., 2013; Nishiya et al., 2014). Figure 1 present the frequency of specific NS3 and NS5b resistance-associated variants found in this study by HCV subtype.

The HCV NS5b sequencing from 63 samples was analyzed. The L320F mutation was present in only one sample $(1.59 \%)$ of genotype $1 \mathrm{a}$. L320F is known to confer low resistance to sofosbuvir and sofosbuvir associated with mericitabine (Paolucci et al., 2013), which are associated to treatment failure in clinical trials (Constantino et al., 2015). In a previous study, L320F single mutation had no significant impact on the $50 \%$ effective concentration (EC50) and EC90 values for mericitabine ( $\leq 2.7$ fold) (Tong et al., 2014). To our knowledge, this is the first time that mutation L320F is reported as naturally occurring in DAA treatment-naïve patients and it should be monitored due to treatment failures reported previously in clinical trials.
The polymorphism $\mathrm{C} 316 \mathrm{~N} / \mathrm{R}$ was present in 4 samples $(6.35 \%)$ of genotype $1 \mathrm{~b} . \mathrm{C} 316 \mathrm{~N}$ is reported to confer low level of resistance to sofosbuvir (Paolucci et al., 2013, Lontok et al., 2015). C316N mutation has been associated with a 10-fold increase in EC50 to a new experimental non-nucleoside drug, HCV796 (Castilho et al., 2011). Previous studies have found variable prevalence of $\mathrm{C} 316 \mathrm{~N}$ in Brazil, from $3.85 \%$ (Peres-da-Silva et al., 2017) to $11.6 \%$ (Castillho et al., 2011), 16.3\% (Noble et al., 2017), and 24\% (Castilho et al., 2011), and higher prevalence in North America (16.81\%), Europe (7.47\%), and Asia (49.71\%) (Peres-da-Silva et al., 2017). The higher prevalence of mutations in genotype $1 \mathrm{~b}$ has been reported previously and it was due to the presence of C316N (Paolucci et al., 2013; Peres-da-Silva et al., 2017).

Although it was not a goal of our study, we also observed the presence of D244N, Q309R, and A333E mutations conferring resistance to ribavirin and interferon in 42 samples $(57.14 \%)$. Twenty samples $(26.98 \%)$ presented Q309R, and three (1.58\%) A333E. Seventeen were Q309R and D244N, two were Q309R and A333E, and two were triple positive. In a previous work, the most frequent mutation observed in Brazil was Q309R, present in all HCV subtypes (Castilho et al., 2011); in our study, it was present in 38 samples. No double mutations in the NS5b region conferring resistance to DAAs was observed in our samples. The emergence of double or triple-sites RAVs in the clinics is threatening the effectiveness of anti-HCV therapies, as published previously (Gane et al., 2016).

The analysis of the NS3 region revealed the mutations D168A/G/T (3.45\%, 3/87), S122G (1.15\%, 1/87), and V55A $(2.3 \%, 2 / 87)$ that confer resistance to asunaprevir, boceprevir, grazoprevir, simeprevir, and paritaprevir (Zeminian et al., 2013; Lontok et al., 2015; Sorbo et al., 2018). V55A was observed at a higher frequencies in previous works, at 4.1\% (Moreira et al., 2018) and 6\% (Nishiya et $a l ., 2014)$, from DAA naïve patients and blood donors, respectively, in São Paulo, and at 6\% in Europe (Bartels et al., 2013). The V55A variant has been shown to confer 6.9-fold increase in EC50 to boceprevir (Vermehren et al., 2012). S122G was found in a higher frequency in Spain (6.23\%) and China (85.48\%) (Li et al., 2017). An in vitro study has shown that S122G did not reduce susceptibility to simeprevir (Izquierdo et al., 2014). However, another study showed that S122G reduced the susceptibility by 0.5 -fold (Lenz et al., 2010). In São Paulo, the D168G mutation was found in one of the $125 \mathrm{HCV}$ infected blood donors' samples (Nishiya et al., 2014). In a transient susceptibility assay, D168G conferred low- to moderate-level asunaprevir resistance (5- to 21-fold) for HCV genotype 1a. For genotype $1 \mathrm{~b}$, a higher level of asunaprevir-associated resistance was observed ranging from 170 - to 400 -fold relative to wild-type control. (McPhee et al., 2012).

No mutations were found that confer resistance to glecaprevir and voxilaprevir, drugs known to present a high 
barrier to resistance (Sorbo et al., 2018). However, this study found samples with mutations that decrease the susceptibility of $\mathrm{HCV}$ to these drugs, which reinforces the importance of monitoring HCV RAVs.

Samples from genotype $3 \mathrm{a}$ presented no mutations that confer or diminish resistance to glecaprevir and voxilaprevir, drugs recommended for treatment of patients infected with this genotype. This means that the standard protocol for treatment of patients with genotype 3 should be effective in Santa Catarina and Rio Grande do Sul. However, we found the non-synonymous mutation V170 I/V in all 32 samples of this genotype. In agreement with our results, Peres-da-Silva (2010) found that $100 \%$ (32/32) of the HCV 3 a sequences contained the V170I substitution. Few data is available on effects of V170I substitution. The conservative substitution at this site was detected in up to $45 \%$ of patients infected with HCV genotype 1 (López-Labrador et al., 2008)

A different pattern of resistance associated with NS3 protease domain in therapy-naïve patients was previously reported in Brazil. V36L mutation was found in genotype $1 \mathrm{a}$ at a frequency of $5.6 \%$, in $1 \mathrm{~b}$ at $100 \%$ (Peres-da-Silva $e t$ al., 2010), and in genotypes 2, 3, 4, and 5 V36L mutation was found as a genetic signature with frequency of $99 \%$ (Vidal et al., 2016); in another work, V36L was found at a frequency of $4 \%$ in genotype 1a (Nishiya et al., 2014). T54S mutations were found in $4.1 \%$ of genotype 1a (Peres-da-Silva et al., 2010) and $100 \%$ in genotype 2 (Vidal et al., 2016). The samples investigated by our study presented none of these mutations. The Q80K, a common mutation in the USA (40\%) (Bartels et al., 2013) that confers resistance to simeprevir, was not found in our study, but has previously been reported at prevalence ranging from $0.4 \%$ to $2.7 \%$ in Brazil (Nishiya et al., 2014; Vidal et al., 2015; Moreira et al., 2018). There is a strong geographic correlation regarding the frequency of the Q80K substitution (Moreira et al., 2018), and for this reason, studies from different geographic regions are of great importance, especially in a large country as Brazil.

Of all the samples evaluated, only one sample of genotype $1 \mathrm{~b}$ showed mutation in the genes NS3 and NS5b, conferring resistance to sofosbuvir $(\mathrm{C} 316 \mathrm{~N})$ and decreased susceptibility to gazoprevir (Y56F). This shows the importance of studying both NS3 and NS5 proteins when evaluating or choosing the therapy strategy for HCV-positive patients. Patients carrying combinations of resistance mutations are of particular interest, since they may increase the possibility of failure in the treatment with DAAs.

The frequency of resistance mutations and genotypes was twice as high among patients with subtype 1a compared to those with subtype $1 \mathrm{~b}$. A similar result was found in a study with blood donor's samples from São Paulo (Nishiya et al., 2014). In addition, a higher frequency of virological failure for subtype $1 \mathrm{a}$ compared to $1 \mathrm{~b}$ has been reported (Pawlotsky et al., 2011).
At last, several polymorphisms not associated with resistance to DAAs were observed in our study (Table 1), and previously reported by others (Constantino et al., 2015). Polymorphisms, prior to therapy, are part of the quasispecies population in infected individuals, and may not alter viral fitness (Peres-da-Silva et al., 2012; Paolucci et al., 2013; Nishiya et al., 2014).

In conclusion, we have shown that mutations in NS3 and NS5b domains are present in Brazilian isolates from therapy-naïve patients, in this case, blood donors with unknown HCV infection. Monitoring the presence of RAVs is important for predicting the response to antiviral therapy, and regional discernment can help determine local policies for treatment. The results presented here will help ensure therapy strategies that are more successful for HCV-infected patients in Santa Catarina and Rio Grande do Sul states in Brazil.

\section{Acknowledgments}

The authors acknowledge financial support from Fundação Oswaldo Cruz, RJ.

Table 1 - HCV polymorphic sites distribution according to genotype.

\begin{tabular}{|c|c|c|c|c|c|}
\hline Gene & Position & Polymorphisms ${ }^{*}$ & $1 \mathrm{a}$ & $1 \mathrm{~b}$ & $3 a$ \\
\hline \multirow[t]{12}{*}{ NS3 } & 62 & R62K & 7 & 3 & 5 \\
\hline & 64 & $\mathrm{I} 64 \mathrm{~L} / \mathrm{M}$ & 7 & 5 & 2 \\
\hline & 86 & P86Q/H & 5 & 2 & 7 \\
\hline & 89 & Q89A/H/P & 8 & 3 & 3 \\
\hline & 91 & $\mathrm{~S} 91 \mathrm{~A} / \mathrm{T}$ & 18 & 11 & 10 \\
\hline & 102 & $\mathrm{~S} 102 \mathrm{~A} / \mathrm{F}$ & 3 & 6 & 8 \\
\hline & 140 & $\mathrm{~T} 140 \mathrm{~A}$ & 22 & & \\
\hline & 147 & $\mathrm{~A} / \mathrm{F} 147 \mathrm{G} / \mathrm{M} / \mathrm{S} / \mathrm{T}$ & 9 & 2 & 8 \\
\hline & 153 & L153I & 24 & 9 & 9 \\
\hline & 166 & $\mathrm{~A} / \mathrm{S} 166 \mathrm{~A} / \mathrm{T} / \mathrm{R}$ & 4 & 5 & 9 \\
\hline & 170 & $\mathrm{I} / \mathrm{V} 170 \mathrm{I} / \mathrm{V} / \mathrm{H}$ & 3 & 2 & 32 \\
\hline & 176 & $\mathrm{E} / \mathrm{S} 176 \mathrm{~K} / \mathrm{N}$ & 8 & 9 & 5 \\
\hline \multirow[t]{12}{*}{ NS5 } & 244 & D244N & & & 17 \\
\hline & 254 & $\mathrm{~K} 254 \mathrm{R} / \mathrm{S}$ & 5 & 13 & 22 \\
\hline & 300 & $\mathrm{R} 300 \mathrm{Q} / \mathrm{S} / \mathrm{T}$ & 17 & 17 & 23 \\
\hline & 309 & Q309R/H & 15 & 1 & 22 \\
\hline & 312 & $\mathrm{~T} 312 \mathrm{D} / \mathrm{E} / \mathrm{S} / \mathrm{R}$ & 2 & 2 & 23 \\
\hline & 329 & $\mathrm{~V} 329 \mathrm{E} / \mathrm{F} / \mathrm{G} / \mathrm{R} / \mathrm{T}$ & 14 & 17 & 7 \\
\hline & 332 & D332G/N/R & 5 & 12 & 13 \\
\hline & 333 & A333E/G/P/Q & 11 & 6 & 23 \\
\hline & 334 & $\begin{array}{c}\mathrm{A} 334 \mathrm{G} / \mathrm{H} / \mathrm{V} / \mathrm{Q} / \\
\mathrm{W}\end{array}$ & 12 & 10 & 17 \\
\hline & 335 & $\mathrm{~S} 335 \mathrm{E} / \mathrm{N} / \mathrm{G} / \mathrm{Q} / \mathrm{T}$ & 15 & 13 & 23 \\
\hline & 336 & L336A/P & 14 & 12 & 20 \\
\hline & 337 & R337N/T/ & 11 & 12 & 9 \\
\hline
\end{tabular}

*Some samples had more than one variant. 


\section{Competing interests}

The authors declare that no competing interests exist.

\section{Author contributions}

PA, AT, RB, AGPF, EA designed the study; EA, DR, MFM, EC, MR conducted the experiments and analyzed the data; EA, DTG, data analysis and wrote the manuscript; AT, PA, critically analyzed the data and manuscript writing. All authors read and approved the final version of the manuscript.

\section{References}

Bartels DJ, Sullivan JC, Zhang EZ, Tigges AM, Dorrian JL, Meyer S, Takemoto D, Dondero E, Kwong AD, Picchio G et al. (2013) Hepatitis $C$ virus variants with decreased sensitivity to direct-acting antivirals (DAAs) were rarely observed in DAA-naïve patients prior to treatment. J Virol 87:15441553.

Ministério da Saúde (2018) Protocolo Clínico e Diretrizes Terapêuticas para Hepatite C. Ministério da Saúde, Brasilia, 108 p.

Campiotto S, Pinho JR, Carrilho FJ, Da Silva LC, Souto FJ, Spinelli V, Pereira LM, Coelho HS, Silva AO and Fonseca JC (2005) Geographic distribution of hepatitis C virus genotypes in Brazil. Braz J Med Biol Res 38:41-49.

Cantaloube JF, Gallian P, Attoui H, Biagini P, Micco P and Lamballerie X (2005) Genotype distribution and molecular epidemiology of hepatitis $\mathrm{C}$ virus in blood donors from southeast France. J Clin Microbiol 43:3624-3629.

Castilho MCB, Martins AN, Horbach IS, Perez RM, Figueiredo FAF, Pinto PTA, Nabuco LC, Lima DB, Tanuri A, Porto LC et al. (2011) Association of hepatites C virus NS5B variants with resistance to new antiviral drugs among untreated patients. Mem Inst Oswaldo Cruz 106:968-975.

Constantino A, Spada E, Equestre M, Bruni R, Triarelli E, Coppola N, Sagnelli C, Sagnelli E and Ciccaglione R (2015) Naturally occuring mutations associated with resistance to HCV NS5b polymerase and NS3 protease inhibitors in treatment-naïve patients with chronic hepatitis C. Virol J 12:186.

Gededzha MP, Mphahlele MJ, Blackard JT and Selabe G (2017) Prevalence of NS5B resistance mutations in hepatitis C virus $(\mathrm{HCV})$ treatment naïve South Africans. Hepat Mon 17:e14248

Gross MJ, Härter G, Backhus J, Zizer E, Seufferlein T, Ludwig L and Dikopoulos N (2018) Direct-acting antiviral agents in the treatment of chronic hepatitis $\mathrm{C}$ - "real-life" experience from an academic centre and two specialized clinical practices. Z Gastroenterol 56:351-360.

Hoffmann L, Ramos JA, Souza EV, Araujo Ramos AL, VillelaNogueira CA, Urményi TP, Tanuri A, Rondinelli E and Silva R (2013) Dynamics of resistance mutations to NS3 protease inhibitors in a cohort of Brazilian patients chronically infected with hepatitis $C$ virus (genotype 1) treated with pegylated interferon and ribavirin: a prospective longitudinal study. Virol J 10:57.

Hoffmann L, Faffe DS, Lima JFC, Capitanio TA, Cabral BCA, Ürméndyi TP, Coelho HSM, Rondinelli E, Villela-Nogueira CA and Silva R (2015) No correspondence between resis- tance mutations in the HCV-NS3 protease at baseline and early telaprevir-based triple therapy. BBA Clinical 3:146151.

Gane E, Ben Ari Z, Mollison L, Zuckerman E, Bruck R, Baruch Y, Howe AY, Wahl J, Bhanja S, Hwang P et al. (2016) Efficacy and safety of grazoprevir + ribavirin for 12 or 24 weeks in treatment-naive patients with hepatitis $\mathrm{C}$ virus genotype 1 infection. J Viral Hepat 23:789-797.

Izquierdo L, Helle F, François C, Castelain S, Duverlie G and Brochot E (2014) Simeprevir for the treatment of hepatitis C virus infection. Pharmgenomics Pers Med 7:241-249.

Kalaghatgi P, Sikorski AM, Knops E, Rupp D, Sierra S, Heger E, Neumann-Fraune M, Beggel B, Walker A, Timm J et al. (2016) Geno2pheno[HCV] - A Web-based interpretation system to support hepatitis $\mathrm{C}$ treatment decisions in the era of direct-acting antiviral agents. Plos One 11:e0155869.

Lampe E, Lewis-Ximenez L, Espirito-Santo MP, Delvaux NM, Pereira SA, Peres-da-Silva A, Martins RMB, Soares MA, Santos AF, Vidal LL et al. (2013) Genetic diversity of HCV in Brazil. Antivir Ther 18:435-444.

Larrat S, Poveda JD, Coudret C, Fusillier K, Magnat N, SignoriSchmuck A, Thibault V and Morand P (2013) Sequencing assays for failed genotyping with the versant hepatitis $\mathrm{C}$ virus genotype assay (LiPA), version 2.0. J Clin Microbiol 51:2815-2821.

Lenz O, Verbinnen T, Lin TI, Vijgen L, Cummings MD, Lindberg J, Berke JM, Dehertogh P, Fransen E, Scholliers A et al. (2010) In vitro resistance profile of the hepatitis $\mathrm{C}$ virus NS3/4A protease inhibitor TMC435. Antimicrob Agents Chemother 54:1878-1887.

Leuw P and Stephan C (2018) Protease inhibitor therapy for hepatitis C virus-infection. Expert Opin Pharmacother 19:577587.

Li Z, Chen ZW, Li H, Ren H and Hu P (2017) Prevalence of hepatitis $\mathrm{C}$ virus-resistant association substitutions to directacting antiviral agents in treatment-naïve hepatitis $\mathrm{C}$ genotype 1b-infected patients in western China. Infect Drug Resist 10:377-392.

Loggi E, Galli S, Vitale G, Donato RD, Vukotic R, Grandini E, Margotti M, Guarneri V, Furlini G, Galli C et al. (2017) Monitoring the treatment of hepatitis $\mathrm{C}$ with directly acting antivirals by serological and molecular methods. PLOS One 12:e0187755.

Lontok E, Harrington P, Howe A, Kieffer T, Lennerstrand J, Lenz O, McPhee F, Mo H, Parkin N, Pilot-Matias T et al. (2015) Hepatitis $\mathrm{C}$ virus drug resistance-associated substitutions: state of the art summary. Hepatology 62:1623-1632.

López-Labrador FX, Moya A and Gonzàlez-Candelas F (2008) Mapping natural polymorphisms of hepatitis $\mathrm{C}$ virus $\mathrm{NS} 3 / 4 \mathrm{~A}$ protease and antiviral resistance to inhibitors in worldwide isolates. Antivir Ther 13:481-94.

McPhee F, Friborg J, Levine S, Chen C, Falk P, Yu F, Hernandez D, Lee M, Chaniewski S, Sheaffer A et al. (2012) Resistance analysis of the hepatitis C virus NS3 protease inhibitor asunaprevir. Antimicrob Agents Chemother 56:3670-3681.

Moreira RC, Santos APT, Lisboa-Neto G, Mendes-Corrêa MCJ, Lemos MF, Malta FM, Santana RAF, Dastoli GTF, Castro VFD and Pinho JRR (2018) Prevalence of naturally occurring amino acid substitutions associated with resistance to hepatites C vírus NS3/NS4A protease inhibitors in São Paulo state. Arch Virol 163:2757-2764. 
Nishiya AS, Almeida-Neto C, Ferreira SC, Alencar CS, DiLorenzo-Oliveira C, Levi JE, Salles NA, Mendrone Jr A and Sabino EC (2014) HCV genotypes, characterization of mutations conferring drug resistance to protease inhibitors, and risk factors among blood donors in São Paulo, Brazil. PLoS One 9:e86413.

Noble CF, Malta F, Lisboa-Neto G, Gomes-Gouvêa MS, Leite AGB, Castro VFD, Santana RAF, Carrilho FJ, MendesCorrea MC and Pinho JRR (2017) Natural occurrence of NS5B inhibitor resisance-associated variants in Brazilian patients infected with HCV or HBV and HIV. Arch Virol 162:165-169.

Paolucci S, Fiorina L, Mariani B, Gulminetti R, Novati S, Barbarini G, Bruno R and Baldanti F (2013) Naturally occurring resistance mutations to inhibitors of HCV NS5A region and NS5B polymerase in DAA treatment-naïve patients. Virol J 10:355.

Pawlotsky JM (2011) Treatment failure and resistance with direct-acting antiviral drugs against hepatitis $\mathrm{C}$ virus. Hepatology 53:1742-1751.

Peres-da-Silva A, Almeida AJ and Lampe E (2010) Mutations in hepatitis $\mathrm{C}$ virus NS3 protease domain associated with resistance to specific protease inhibitors in antiviral therapy naïve patients. Arch Virol 155:807-811.

Peres-da-Silva A, Almeida AJ and Lampe E (2012) Genetic diversity of NS3 protease from Brazilian HCV isolates and possible implications for therapy with direct-acting antiviral drugs. Mem Inst Oswaldo Cruz 107:254-261.

Peres-da-Silva A, Brandão-Mello CE and Lampe E (2017) Prevalence of sofosbuvir resistance-associated variants in Brazilian and worldwide NS5B sequences of genotype-1 HCV. Antivir Ther 22:447-451.

Sandres-Sauné K, Deny P, Pasquier C, Thibaut V, Duvelier G and Izopet J (2003) Determining hepatitis $\mathrm{C}$ genotype by analyzing the sequence of the NS5b region. J Virol Methods 109:187-93.

Sette Jr H, Cheinquer H, Wolff FH, Araujo A, Coelho-Borges S, Soares SRP and Barros MFA (2017) Treatment of chronic $\mathrm{HCV}$ infection with the new Direct Acting Antivirals (DAA): first report of a real world experience in southern Brazil. Ann Hepatol 16:727-733.

Scott JD and Gretch DR (2007) Molecular diagnostics of hepatitis C virus infection: a systematic review. JAMA 297:724-732.

Smith DB, Bukh J, Kuiken C, Muerhoff AS, Rice CM, Stapleton JT and Simmonds P (2014) Expanded classification of hepatitis $\mathrm{C}$ virus into 7 genotypes and 67 subtypes: updated crite- ria and genotype assignment web resource. Hepatology 59:318-327.

Sorbo MC, Cento V, Di Maio VC, Howe AYM, Garcia F, Perno $\mathrm{CF}$ and Ceccherini-Silberstein F (2018) Hepatitis C virus drug resistance associated substitutions and their clinical relevance: Update 2018. Drug Resist Updat 37:17-39.

Soriano V, Mocroft A, Rockstroh J, Ledergerber B, Knysz B, Chaplinskas S, Peters L, Karlsson A, Katlama C, Toro C et al. (2008) Spontaneous viral clearance, viral load, and genotype distribution of hepatitis $\mathrm{C}$ virus (HCV) in HIV-infected patients with anti-HCV antibodies in Europe. J Infect Dis 198:1337-1344.

Tong X, Le Pogam S, Li L, Haines K, Piso K, Baronas V, Yan JM, So SS, Klumpp K and Nájera I (2014) In vivo emergence of a novel mutant L159F/L320F in the NS5B polymerase confers low-level resistance to the HCV polymerase inhibitors mericitabine and sofosbuvir. J Infect Dis 209:668-675.

Vermehren J, Susser S, Lange CM, Forestier N, Karey U, Hughes E, Ralston R, Tong X, Zeuzem S and Sarrazin C (2012) Mutations selected in the hepatitis $\mathrm{C}$ virus NS3 protease domain during sequential treatment with boceprevir with and without pegylated interferon alfa-2b. J Viral Hepat 19:120-127.

Vidal LL, Santos AF and Soares MA (2015) Worldwide distribution of the NS3 gene $80 \mathrm{~K}$ polymorphism among circulating hepatitis $\mathrm{C}$ genotype 1 viruses: implication for simeprevir usage. J Antimicrob Chemother 70:2024-2027.

Vidal LL, Soares MA and Santos AF (2016) NS3 protease polymorphisms and genetic barrier to drug resistance of distinct hepatites $\mathrm{C}$ virus genotypes from worldwide treatmentnaïve subjects. J Viral Hepat 23:840-849.

Zeminian LB, Padovani JL, Corvino SM, Silva GF, Pardini MI and Grotto RMT (2013) Variability and resistance mutations in the hepatitis $\mathrm{C}$ virus NS3 protease in patients not treated with protease inhibitors. Mem Inst Oswaldo Cruz 108:1317.

\section{Internet Resources}

WHO (2017) WHO Global hepatitis report, http://www.who.int/hepatitis/publications/global-hepatitis-report2017/en/.

Associate Editor: Carlos F.M. Menck

License information: This is an open-access article distributed under the terms of the Creative Commons Attribution License (type CC-BY), which permits unrestricted use, distribution and reproduction in any medium, provided the original article is properly cited. 